\title{
Analisis Kepuasan Taruna Terhadap Fasilitas Perpustakaan Dalam Rangka Menyiapkan Sumber Daya Manusia Pada Era Society 5.0
}

\author{
(Cadet Satisfaction Analysis On Library Facilities \\ In Order To Prepare Human Resources In The Era Of Society 5.0 \\ At The Indonesian Air Force Academy)
}

\author{
Rezki Fitra Ramadhan ${ }^{*}$, Gagat Riano², Agus Pudjianto ${ }^{3}$, Ismoyo $^{4}$ \\ 1,2,3,4 Departemen Teknik Manajemen Industri, Akademi Angkatan Udara, Yogyakarta, Indonesia \\ E-mail :rezkifitra2150@gmail.com,gagat.riano@aau.ac.id,agus_pudji@aau.ac.id,bambang.imy@aau.ac.id
}

Abstract- The Indonesian Air Force Academy Library is a facility prepared by the Indonesian Air Force Academy whose task is to carry out support for the cadets and users in every activity at the Indonesian Air Force Academy. In this case, the AAU's library also requires attention, especially in terms of care and maintenance of the facilities in the AAU's library. To find out the cadet's satisfaction with the facilities in the $A A U$ 's library, it was done by distributing questionnaires to 36 respondents to find out the actual value and the expected value received by the cadets or SERVQUAL SCORE. The measurement of cadet's satisfaction is carried out on five dimensions, namely tangible, reliability, assurance, responsiveness, and empathy. From the measurement results, it is known that the 5 SERVQUAL dimension values have an actual value of 6.7 and an expected value of 7.4 so that there is still a gap of -0.7 . From this gap, each attribute is grouped into four quadrants based on the priority of improvement using the IPA (Importance-Performance Analysis) diagram.

Keywords-Libraries, dimensions of service quality, SERVQUAL.

Abstrak- Perpustakaan Akademi Angkatan Udara adalah fasilitas yang disiapkan oleh Akademi Angkatan Udara yang bertugas untuk melaksanakan dukungan untuk para Taruna dan pemustaka dalam setiap kegiatan yang berada di Akademi Angkatan Udara. Dalam hal ini perpustakaan AAU juga memerlukan perhatian, khususnya dalam segi perawatan dan pemeliharaan terhadap fasilitas yang berada di perpustakaan AAU. Untuk mengetahui kepuasan Taruna terhadap fasilitas yang berada di perpustakaan AAU, dilakukan dengan menyebar kuesioner kepada 36 responden untuk mengetahui nilai aktual dan nilai harapan yang diterima Taruna atau SCORE SERVQUAL. Pengukuran kepuasan Taruna dilakukan terhadap lima dimensi yaitu tangible, reliability, assurance, responsiveness, dan emphaty. Dari hasil pengukuran diketahui 5 nilai dimensi SERVQUAL memiliki nilai aktual sebesar 6,7 dan nilai harapan 7,4 sebesar sehingga masih terdapat gap -0,7 . Dari gap tersebut masing-masing atribut dikelompokkan menjadi empat kuadran berdasarkan prioritas perbaikan dengan menggunakan diagram IPA (Importance-Performance Analysis).

Kata Kunci : Perpustakaan, dimensi kualitas jasa, SERVQUAL.

\section{Pendahuluan}

$\mathrm{P}^{\mathrm{s}}$ erkembangan ilmu pengetahuan dan teknologi yang sangat pesat, mendorong manusia mengembangkan suatu konsep untuk memanfaatkan hal tersebut agar kehidupannya menjadi lebih nyaman, dimana saat ini yang terbaru adalah konsep society 5.0. Konsep yang awalnya diperkenalkan oleh Jepang pada tahun 2019 muncul untuk menjawab segala permasalahan yang timbul akibat revolusi

* Penulis Korespondensi (Rezki Fitra Ramadhan)

E-mail: rezkifitra2150@gmail.com 
4.0 yang dinilai berpotensi mendegradasi peran manusia [1] . Konsep society 5.0 mengintegrasikan dunia virtual dengan realita dan memungkinkan manusia untuk dapat menyelesaikan berbagai permasalahan sosial dengan dukungan teknologi. Teknologi kecerdasan buatan (artificial intelligence) akan mentransformasi big data yang dikumpulkan melalui internet pada segala bidang kehidupan (the Internet of Things) menjadi suatu konsep kehidupan baru, yang akan membantu manusia menjalani kehidupan yang lebih baik [2] .

Untuk menghadapi hal tersebut, peran dunia pendidikan sangat strategis, terutama untuk meningkatkan kualtas sumber daya manusia (SDM). Di era society 5.0 manusia dituntut untuk memiliki kemampuan berpikir Higher Order Thinking Skills (HOTS), agar dapat meminimalisir kesenjangan pola pikir dan orientasi teknologi individu, sehingga terbentuk manusia dapat berintegrasi sepenuhnya dengan teknologi tanpa menimbulkan gejola dirupsi. Manusia dituntut untuk lebih cepat menghasilkan solusi dalam memenuhi kebutuhannya [2]. Keadaan ini mendorong manusia untuk terus mengali informasi, serta menciptakan inovasi baru guna menunjang kelangsungan hidupnya.

Akademi Angkatan Udara (AAU) mempunyai peran penting untuk menyiapkan SDM prajurit TNI Angkatan Udara setingkat perwira pertama. Para perwira ini nantinya diharapkan mampu mengemban tugas sebagai prajurit TNI AU serta terus dapat mengembangkan kemampuannya sejalan dengan perkembangan teknologi di era society 5.0. Hal ini telah tersirat dalam sasaran pendidikan yang ditujukan untuk membentuk Taruna yang memiliki sifat Tri Sakti Viratama, yaitu sikap dan perilaku yang dapat diandalkan (tanggon), dapat beradaptasi dengan perkembangan ilmu pengetahuan dan teknologi (Tanggap) serta tangkas dan terampil di bidang latihan jasmani dan kemiliteran (Trengginas) [3]. Untuk itu AAU harus dapat menyiapkan seluruh aspek-aspek pendidikan yang ada di lembaga yang dikenal dengan 10 komponen pendidikan. Sebagai salah satu komponen pendidikan tersebut adalah sarana dan prasana yang mendukung kegiatan belajar mengajar di AAU, contohnya perpustakaan. Perpustakaan merupakan suatu tempat yang berupaya untuk memelihara dan meningkatkan efisiensi dan efektivitas proses belajar-mengajar. Perpustakaan yang terorganisasi secara baik dan sistematis, secara langsung ataupun tidak langsung dapat memberikan kemudahan bagi proses belajar mengajar di sekolah maupun institusi pendidikan tempat perpustakaan tersebut berada [4]. Hal ini, terkait dengan kemajuan bidang pendidikan dan dengan adanya perbaikan metode belajar-mengajar yang dirasakan tidak bisa dipisahkan dari masalah penyediaan fasilitas dan sarana pendidikan. Fasilitas yang disediakan perpustakaan AAU sangat baik, karena perpustakaan yang berada di AAU sudah mengalami renovasi. Namun, yang menjadi permasalahan adalah masih ditemui beberapa kekurangan yang berada di Perpustakaan Akademi Angkatan Udara. Hal ini dapat terlihat dari beberapa Taruna yang mengeluhkan mengenai fasilitas yang kurang maksimal. Oleh karena itu sangat diperlukan penelitian mengenai fasilitas perpustakaan terhadap tingkat kepuasan Taruna agar perpustakaan Akademi Angkatan Udara dapat lebih optimal lagi [5].

Dari permasalahan tersebut peneliti mencoba menganalisis fasilitas perpustakaan terhadap kepuasan Taruna dengan menggunakan metode service quality yang merupakan metode yang cocok dalam pembuatan penelitian ini. Hal ini bertujuan untuk mengukur tingkat kepuasan Taruna yang ada di Akademi Angkatan Udara.

\section{LANDASAN TEORI}

Menurut Zeithaml [6] servqual dapat didefinisikan sebagai seberapa jauh perbedaan antara kenyataan dan harapan pelanggan atas pelayanan yang mereka terima/peroleh. Harapan para pelanggan pada dasarnya sama dengan layanan seperti apakah seharusnya diberikan oleh perusahaan kepada pelanggan. Menurut penelitian yang dilakukan oleh Parasuraman dan kawan-kawan disimpulkan dari ke-5 dimensi tersebut terdapat kepentingan relatif yang berbeda-beda. Menurut Parasuraman [7], ada 5 dimensi SERVQUAL sebagai berikut [8]: 
1. Tangibles, atau bukti fisik yaitu kemampuan suatu perusahaan dalam menunjukkan eksistensinya pada pihak eksternal. Penampilan dan kemampuan sarana dan prasarana fisik perusahaan dan keadaan lingkungan sekitarnya adalah bukti nyata dari pelayanan yang diberikan oleh pemberi jasa. ini meliputi fasilitas fisik (Gedung, Gudang, dan lainnya), teknologi (peralatan dan perlengkapan yang dipergunakan), serta penampilan pegawainya. Secara singkat dapat diartikan sebagai penampilan fasilitas fisik, peralatan, personil, dan materi komunikasi.

2. Reliability, atau keandalan yaitu kemampuan perusahaan untuk memberikan pelayanan sesuai yang dijanjikan secara akurat dan terpercaya. Harus sesuai dengan harapan pelanggan berarti kinerja yang tepat waktu, pelayanan tanpa kesalahan, sikap simpatik dan dengan akurasi tinggi. Secara singkat dapat diartikan sebagai kemampuan untuk memberikan layanan yang dijanjikan secara akurat, tepat waktu, dan dapat dipercaya.

3. Responsiveness, atau ketanggapan yaitu suatu kemauan untuk membantu dan memberikan pelayanan yang cepat (responsive) dan tepat kepada pelanggan, dengan penyampaian informasi yang jelas. Membiarkan konsumen menunggu tanpa alasan yang jelas menyebabkan persepsi yang negatif dalam kualitas pelayanan. Secara singkat dapat diartikan sebagai kemauan untuk membantu pelanggan dengan memberikan layanan yang baik dan cepat.

4. Assurance, atau jaminan dan kepastian yaitu pengetahuan, kesopan santunan, dan kemampuan para pegawai perusahaan untuk menumbuhkan rasa percaya pelanggan kepada perusahaan. Terdiri dari komponen: komunikasi (Communication), kredibilitas (Credibility), keamanan (Security), kompetensi (Competence), dan sopan santun (Courtesy). Secara singkat dapat diartikan sebagai pengetahuan dan keramahtamahan personil dan kemampuan personil untuk dapat dipercaya dan diyakini. [9].

5. Empathy, yaitu memberikan perhatian yang tulus dan bersifat individual atau pribadi yang diberikan kepada pelanggan dengan berupaya memahami keinginan konsumen dimana suatu perusahaan diharapkan memiliki suatu pengertian dan pengetahuan tentang pelanggan, memahami kebutuhan pelanggan secara spesifik, serta memiliki waktu pengoperasian yang nyaman bagi pelanggan. Secara singkat dapat diartikan sebagai usaha untuk mengetahui dan mengerti kebutuhan pelanggan secara individual. Menurut Parasuraman, dkk (1990), Reliability secara konsisten merupakan dimensi paling kritis, kemudian tingkat ke-2 assurance, ke-3 oleh tangibles (terutama oleh perusahaan perbankan), ke-4 oleh responsiveness, dan kadar kepentingan yang paling rendah adalah empathy.

\section{Metode Penelitian}

Pengukuran kualitas jasa dalam model Servqual ini didasarkan pada skala multiitem yang dirancang untuk mengukur harapan dan persepsi pelanggan. Serta Gap diantara keduanya pada lima dimensi kualitas jasa yaitu (Reliabitity, daya tanggap, jaminan, Empaty dan Bukti fisik), kelima dimensi kualitas tersebut dijabarkan dalam beberapa butir pertanyaan untuk atribut harapan dan variabel presepsi berdasarkan skala likert. Skor Servqual untuk tiap pasang pertanyaan bagi masing-masing pelanggan dapat dihitung berdasarkan rumus berikut Zeithalm [7] dalam Tjiptono [10].

\section{SKOR SERVQUAL = SKOR AKTUAL - SKOR HARAPAN}

Secara garis besar langkah langkah dalam penggunaan metode service quality adalah sebagai berikut:

a. Tentukan rata-rata nilai persepsi (P) untuk setiap variabel.

$$
\mathrm{P}=\frac{\sum_{i-1}^{n} p i}{n}
$$

Dimana : $\quad \mathrm{Pi}=$ Nilai persepsi yang diberikan pelanggan atau manajemen untuk pertanyaan ke-i 
$\mathrm{n}=$ Jumlah responden

b. Tentukan rata-rata nilai harapan (E) untuk setiap variabel.

$$
E=\frac{\sum \frac{n}{1=i} E i}{n}
$$

Dimana : $\quad$ Ei $=$ Nilai harapan yang diberikan pelanggan untuk pertanyaan ke-i

$\mathrm{n}$ = Jumlah responden

c. Tentukan Servqual Score (S) untuk setiap variabel

$$
\mathrm{S}=P-E
$$

Untuk meningkatkan kualitas layanan perpustakaan, digunakan Importance Performance Analysis (IPA) sebagai alat bantu dalam penelitian ini, agar pihak perpustakaan dapat menentukan tindakan perbaikan sesuai dengan urutan prioritas. Adapun interpretasi dari masing-masing kuadran yaitu :

a. Kuadran I. Atribut-atribut yang terletak pada kuadran I merupakan atribut yang sangat krusial dan harus segera ditindak lanjuti.

b. Kuadran II. Atribut-atribut yang terletak pada kuadran ini dinilai cukup baik dan mampu untuk dipertahankan.

c. Kuadran III. Atribut-atribut yang terletak pada kuadran ini merupakan atribut yang tidak terlalu membutuhkan perhatian khusus.

d. Kuadran IV. Atribut-atribut yang terletak pada kuadran ini dianggap tidak terlalu penting sehingga pihak manajemen perlu mengalokasikan sumber daya yang terkait dengan atribut-atribut

\begin{tabular}{|c|c|}
\hline $\begin{array}{c}\text { QUADRANT I } \\
\text { Concentrate Here } \\
\text { High Importance } \\
\text { Low Performance }\end{array}$ & $\begin{array}{c}\text { QUADRANT II } \\
\text { Keep Up the Good Work } \\
\text { High Importance } \\
\text { High Performance }\end{array}$ \\
\hline $\begin{array}{l}\text { QUADRANT III } \\
\text { Low Priority } \\
\text { Low Importance } \\
\text { Low Performance }\end{array}$ & $\begin{array}{l}\text { QUADRANT IV } \\
\text { Possible Overkill } \\
\text { Low Importance } \\
\text { High Performance }\end{array}$ \\
\hline
\end{tabular}
tersebut kepada atribut-atribut lain yang mempunyai prioritas penanganan lebih tinggi.

PERFORMANCE

Gambar 1. Kuadran Importance-Performance Analysis

\section{IMPLEMENTASI MODEL DAN PEMBAHASAN}

Responden pada penelitian ini adalah Taruna Tk. III W 2018 Prodi Teknik Manajemen Industri Akademi Angkatan Udara yang sedang melaksanakan tugas akhir sejumlah 36 orang terdiri dari 33 
Taruna laki-laki (91,7\%) dan 3 Taruni (8,3\%). Data ini diambil untuk menganalisis tingkat kepuasan Taruna terhadap fasilitas yang berada di perpustakaan AAU dengan menggunakan metode Service Quality (SERVQUAL). Setelah mendapatkan hasil data dari kuesioner tersebut maka selanjutnya data tersebut akan dilakukan pengujian validitas dan reabilitas menggunakan SPPS. Dalam penelitian ini akan dilakukan pengumpulan data untuk mengetahui tingkat kepuasan Taruna terhadap fasilitas yang disediakan perpustakaan AAU dimana perpustakaan tersebut sering digunakan Taruna pada saat jam studi pustak. Maka penulis melakukan penelitian ini kepada Taruna yang sudah pernah menggunakan perpustakaan AAU tersebut untuk mengetahui tingkat kepuasan Taruna terhadap fasilitas yang disediakan perpustakaan AAU.

TABLE I.

ANGKET RESPONDEN

\begin{tabular}{|c|c|c|c|c|c|c|c|c|c|c|c|}
\hline \multirow{2}{*}{ ATRIBUT } & \multirow{2}{*}{$\mathrm{NO}$} & \multirow{2}{*}{ KETERANGAN ATRIBUT } & \multicolumn{5}{|c|}{ HARAPAN } & \multicolumn{4}{|c|}{ AKTUAL } \\
\hline & & & 1 & 2 & 3 & 4 & 5 & 1 & 2 & 3 & \\
\hline \multirow{2}{*}{$\begin{array}{l}\text { RELIABILITYI } \\
\text { KEHANDALAN }\end{array}$} & 1 & $\begin{array}{l}\text { Perpustakaan AAU memiliki petunjuk judul dan } \\
\text { jenis buku yang lengkap }\end{array}$ & & & & & & & & & \\
\hline & 2 & $\begin{array}{l}\text { Perpustakaan AAU memiliki referensi selain } \\
\text { buku seperti majalah dan koran }\end{array}$ & & & & & & & & & \\
\hline \multirow{4}{*}{$\begin{array}{l}\text { ASSURANCE/ } \\
\text { JAMINAN }\end{array}$} & 3 & $\begin{array}{l}\text { Petugas perpustakaan melayani pemustaka } \\
\text { dengan bahasa yang sopan }\end{array}$ & & & & & & & & & \\
\hline & 4 & $\begin{array}{l}\text { Petugas perpustakaan memiliki ketelitian dalam } \\
\text { melayani pemustaka }\end{array}$ & & & & & & & & & \\
\hline & 5 & $\begin{array}{l}\text { Petugas perpustakaan memiliki pengetahuan } \\
\text { yang luas tentang buku buku yang ada }\end{array}$ & & & & & & & & & \\
\hline & 6 & $\begin{array}{l}\text { Perpustakaan memiliki jam operasional yang } \\
\text { sesuai dengan keinginan pemustaka }\end{array}$ & & & & & & & & & \\
\hline \multirow{4}{*}{$\begin{array}{c}\text { RESPONSIVENESS/ } \\
\text { KETANGGAPA } \\
\mathrm{N}\end{array}$} & 7 & $\begin{array}{l}\text { Penataan buku di perpustakaan sudah sesuai } \\
\text { sehingga mudah ditemukan }\end{array}$ & & & & & & & & & \\
\hline & 8 & Perpustakaan memiliki denah tata letak buku & & & & & & & & & \\
\hline & 9 & $\begin{array}{l}\text { Perpustakaan memiliki kecepetan dalam } \\
\text { pelayanan kepada pemustaka }\end{array}$ & & & & & & & & & \\
\hline & 10 & $\begin{array}{l}\text { Petugas perpustakaan merespon dengan cepat } \\
\text { dalam menanggapi pertanyaan pemustaka }\end{array}$ & & & & & & & & & \\
\hline \multirow{4}{*}{$\begin{array}{l}\text { TANGIBLE/ } \\
\text { BUKTI FISIK }\end{array}$} & 11 & $\begin{array}{l}\text { Buku buku yang ada di perpustakaan sudah } \\
\text { lengkap }\end{array}$ & & & & & & & & & \\
\hline & 12 & Perpustakaan memiliki lingkungan yang bersih & & & & & & & & & \\
\hline & 13 & $\begin{array}{l}\text { Petugas perpustakaan memiliki penampilan yang } \\
\text { rapi }\end{array}$ & & & & & & & & & \\
\hline & 14 & $\begin{array}{l}\text { Perpustakaan menyediakan peralatan kantor } \\
\text { yang memadai seperti alat tulis, printer, atau } \\
\text { mesin fotocopy }\end{array}$ & & & & & & & & & \\
\hline \multirow{4}{*}{$\begin{array}{l}\text { EMPATHYI } \\
\text { EMPATI }\end{array}$} & 15 & $\begin{array}{l}\text { Petugas perpustakaan melayani pemustaka } \\
\text { dengan sikap yang ramah }\end{array}$ & & & & & & & & & \\
\hline & 16 & $\begin{array}{l}\text { Petugas perpustakaan memiliki etika yang baik } \\
\text { dalam berkomunikasi dengan pemustaka }\end{array}$ & & & & & & & & & \\
\hline & 17 & $\begin{array}{l}\text { Petugas perpustakaan dapat memahami } \\
\text { kebutuhan pemustakaa seperti memberi } \\
\text { informasi tentang buku buku }\end{array}$ & & & & & & & & & \\
\hline & 18 & $\begin{array}{l}\text { Petugas perpustakaan berusaha menjalin } \\
\text { hubungan baik dengan pemustaka }\end{array}$ & & & & & & & & & \\
\hline
\end{tabular}




\begin{tabular}{|c|c|c|c|c|c|c|}
\hline \multirow[b]{3}{*}{ Atribut } & \multicolumn{5}{|c|}{$\begin{array}{c}\text { TABEL II } \\
\text { EKAPITULASI AKTUAL ANGKET RESPONDEN } \\
\end{array}$} & \multirow[b]{3}{*}{ Total } \\
\hline & \multicolumn{5}{|c|}{ Jumlah jawaban } & \\
\hline & $\begin{array}{c}\text { Sangat } \\
\text { Tidak } \\
\text { Setuju } \\
1\end{array}$ & $\begin{array}{c}\text { Tidak } \\
\text { Setuju } \\
2\end{array}$ & $\begin{array}{c}\text { Cukup } \\
3\end{array}$ & $\begin{array}{c}\text { Setuju } \\
4\end{array}$ & $\begin{array}{c}\text { Sangat } \\
\text { Setuju } \\
5\end{array}$ & \\
\hline 1 & 2 & 3 & 4 & 5 & 6 & 7 \\
\hline Atribut 1 & 5 & 3 & 4 & 12 & 12 & 36 \\
\hline Atribut 2 & 1 & 1 & 9 & 12 & 13 & 36 \\
\hline Atribut 3 & 5 & 7 & 16 & 3 & 5 & 36 \\
\hline Atribut 4 & 3 & 3 & 12 & 6 & 12 & 36 \\
\hline Atribut 5 & 7 & 7 & 7 & 0 & 15 & 36 \\
\hline Atribut 6 & 4 & 5 & 6 & 7 & 14 & 36 \\
\hline Atribut 7 & 0 & 8 & 5 & 7 & 16 & 36 \\
\hline Atribut 8 & 2 & 11 & 6 & 5 & 12 & 36 \\
\hline Atribut 9 & 5 & 10 & 5 & 8 & 8 & 36 \\
\hline Atribut 10 & 0 & 0 & 7 & 9 & 20 & 36 \\
\hline Atribut 11 & 9 & 5 & 9 & 6 & 7 & 36 \\
\hline Atribut 12 & 4 & 6 & 9 & 0 & 17 & 36 \\
\hline Atribut 13 & 3 & 6 & 9 & 3 & 15 & 36 \\
\hline Atribut 14 & 4 & 12 & 3 & 4 & 13 & 36 \\
\hline Atribut 15 & 4 & 16 & 8 & 4 & 4 & 36 \\
\hline Atribut 16 & 12 & 6 & 1 & 14 & 3 & 36 \\
\hline Atribut 17 & 4 & 6 & 3 & 9 & 14 & 36 \\
\hline Atribut 18 & 9 & 8 & 7 & 4 & 8 & 36 \\
\hline Total & 81 & 120 & 126 & 113 & 208 & 648 \\
\hline
\end{tabular}

TABEL III

REKAPITULASI HARAPAN ANGKET RESPONDEN

\begin{tabular}{|c|c|c|c|c|c|c|}
\hline \multirow[b]{2}{*}{ Atribut } & \multicolumn{5}{|c|}{ Jumlah jawaban } & \multirow[b]{2}{*}{ Total } \\
\hline & $\begin{array}{c}\text { Sangat } \\
\text { Tidak } \\
\text { Setuju } \\
1\end{array}$ & $\begin{array}{c}\text { Tidak } \\
\text { Setuju } \\
2\end{array}$ & $\begin{array}{c}\text { Cukup } \\
3\end{array}$ & $\begin{array}{c}\text { Setuju } \\
4\end{array}$ & $\begin{array}{c}\text { Sangat } \\
\text { Setuju } \\
5\end{array}$ & \\
\hline 1 & 2 & 3 & 4 & 5 & 6 & 7 \\
\hline Atribut 1 & 6 & 1 & 2 & 8 & 19 & 36 \\
\hline Atribut 2 & 2 & 0 & 5 & 7 & 22 & 36 \\
\hline Atribut 3 & 5 & 5 & 13 & 4 & 9 & 36 \\
\hline Atribut 4 & 2 & 3 & 10 & 4 & 17 & 36 \\
\hline Atribut 5 & 5 & 6 & 5 & 0 & 20 & 36 \\
\hline Atribut 6 & 3 & 4 & 6 & 5 & 18 & 36 \\
\hline Atribut 7 & 0 & 7 & 3 & 5 & 21 & 36 \\
\hline Atribut 8 & 3 & 6 & 2 & 4 & 24 & 36 \\
\hline Atribut 9 & 4 & 8 & 5 & 6 & 13 & 36 \\
\hline Atribut 10 & 0 & 0 & 6 & 7 & 23 & 36 \\
\hline Atribut 11 & 5 & 6 & 8 & 5 & 12 & 36 \\
\hline Atribut 12 & 2 & 6 & 10 & 1 & 17 & 36 \\
\hline Atribut 13 & 1 & 6 & 9 & 4 & 16 & 36 \\
\hline Atribut 14 & 3 & 11 & 3 & 4 & 15 & 36 \\
\hline
\end{tabular}


TABEL III LANJUTAN

\begin{tabular}{|c|c|c|c|c|c|c|}
\hline \hline $\mathbf{1}$ & $\mathbf{2}$ & $\mathbf{3}$ & $\mathbf{4}$ & $\mathbf{5}$ & $\mathbf{6}$ & $\mathbf{7}$ \\
\hline Atribut 15 & 3 & 16 & 8 & 4 & 5 & 36 \\
\hline Atribut 16 & 10 & 6 & 1 & 14 & 5 & 36 \\
\hline Atribut 17 & 3 & 3 & 3 & 9 & 18 & 36 \\
\hline Atribut 18 & 7 & 8 & 7 & 4 & 10 & 36 \\
\hline Total & 64 & 102 & 106 & 95 & 284 & 648 \\
\hline \hline
\end{tabular}

Dalam hal ini data yang sudah didapat akan diuji terlebih dahulu untuk memastikan apakah data data yang terkumpul sudah cocok dan sudah valid dengan tujuan dari penelitian yang akan dilaksanakan. Pengujian ini akan menggunakan bantuan SPSS untuk menguji validitas data dan reliable data. dikarenakan jumlah responden yang digunakan dalam pencarian uji validitas berjumlah 20, maka $\mathrm{n}-2$ $=20-2=18$, maka $\mathrm{R}$ tabel yang didapat adalah 0,443

Uji Validitas. Uji validitas digunakan untuk mengetahui keakuratan angket dalam pengumpulan data. Uji validitas dilaksanakan dengan rumus korelasi brivalate person dengan alat bantu program SPPS versi 16,0. Item angket dalam uji validitas dikatakan valid apabila jika rhitung > rtabel pada nilai signifikasi 5\%. Hasil uji validitas tabel tabel diatas, menunjukan bahwa semua harga rhitung > rtabel pada nilai signifikasi 5\%. Oleh karena itu, dapat disimpulkan bahwa seluruh item di dalam angket penelitian ini adalah valid, sehingga data tersebut dapat digunakan sebagai penelitian.

TABEL IV

VALIDITAS AKTUAL

\begin{tabular}{|l|r|r|r|r|r|}
\hline & $\begin{array}{c}\text { Scale Mean if } \\
\text { Item Deleted }\end{array}$ & $\begin{array}{c}\text { Scale Variance } \\
\text { if Item Deleted }\end{array}$ & $\begin{array}{c}\text { Corrected Item- } \\
\text { Total } \\
\text { Correlation }\end{array}$ & $\begin{array}{c}\text { Squared } \\
\text { Multiple } \\
\text { Correlation }\end{array}$ & $\begin{array}{c}\text { Cronbach's } \\
\text { Alpha if Item } \\
\text { Deleted }\end{array}$ \\
\hline VAR00001 & 57.5500 & 216.366 & .591 & .860 & .903 \\
\hline VAR00002 & 57.3000 & 222.537 & .559 & .951 & .904 \\
\hline VAR00003 & 58.2500 & 217.145 & .674 & .924 & .901 \\
\hline VAR00004 & 57.6500 & 214.239 & .688 & .967 & .900 \\
\hline VAR00005 & 57.7500 & 214.513 & .577 & .922 & .903 \\
\hline VAR00006 & 57.4500 & 220.997 & .450 & .888 & .907 \\
\hline VAR00007 & 57.3500 & 217.818 & .642 & .933 & .902 \\
\hline VAR00008 & 57.3500 & 215.818 & .577 & .893 & .903 \\
\hline VAR00009 & 57.9000 & 215.253 & .572 & .795 & .904 \\
\hline VAR00010 & 56.7000 & 228.221 & .588 & .946 & .905 \\
\hline VAR00011 & 57.9000 & 218.200 & .549 & .974 & .904 \\
\hline VAR00012 & 57.5500 & 215.734 & .573 & .939 & .904 \\
\hline VAR00013 & 57.1000 & 224.516 & .487 & .545 & .906 \\
\hline VAR00014 & 57.4500 & 217.313 & .509 & .905 & .906 \\
\hline VAR00015 & 58.4000 & 222.779 & .567 & .862 & .904 \\
\hline VAR00016 & 58.4000 & 212.253 & .680 & .877 & .900 \\
\hline VAR00017 & 57.6500 & 216.661 & .552 & .897 & .904 \\
\hline VAR00018 & 58.1500 & 217.187 & .518 & .946 & .905 \\
\hline
\end{tabular}


TABEL V

VALIDITAS HARAPAN

\begin{tabular}{|l|r|r|r|r|r|}
\hline \hline & $\begin{array}{c}\text { Scale Mean if } \\
\text { Item Deleted }\end{array}$ & $\begin{array}{c}\text { Scale Variance } \\
\text { if Item Deleted }\end{array}$ & $\begin{array}{c}\text { Corrected Item- } \\
\text { Total } \\
\text { Correlation }\end{array}$ & $\begin{array}{c}\text { Squared } \\
\text { Multiple } \\
\text { Correlation }\end{array}$ & $\begin{array}{c}\text { Cronbach's } \\
\text { Alpha if Item } \\
\text { Deleted }\end{array}$ \\
\hline VAR00001 & 63.5000 & 347.947 & .865 & .968 & .954 \\
\hline VAR00002 & 62.8000 & 372.379 & .748 & .954 & .956 \\
\hline VAR00003 & 63.4000 & 358.253 & .810 & .908 & .955 \\
\hline VAR00004 & 63.2000 & 359.958 & .730 & .963 & .956 \\
\hline VAR00005 & 63.1000 & 356.621 & .731 & .993 & .956 \\
\hline VAR00006 & 63.0500 & 358.576 & .745 & .975 & .956 \\
\hline VAR00007 & 63.3000 & 365.695 & .689 & .922 & .957 \\
\hline VAR00008 & 62.9500 & 359.839 & .747 & .979 & .956 \\
\hline VAR00009 & 63.5500 & 350.261 & .801 & .927 & .955 \\
\hline VAR00010 & 62.6000 & 375.305 & .746 & .984 & .957 \\
\hline VAR00011 & 63.6500 & 354.976 & .700 & .976 & .956 \\
\hline VAR00012 & 63.5000 & 354.895 & .737 & .957 & .956 \\
\hline VAR00013 & 63.1000 & 359.463 & .696 & .883 & .956 \\
\hline VAR00014 & 63.1500 & 356.345 & .676 & .930 & .957 \\
\hline VAR00015 & 64.2000 & 355.958 & .692 & .973 & .957 \\
\hline VAR00016 & 64.3000 & 347.695 & .827 & .970 & .954 \\
\hline VAR00017 & 63.4000 & 351.095 & .726 & .983 & .956 \\
\hline VAR00018 & 63.9500 & 350.892 & .712 & .982 & .956 \\
\hline
\end{tabular}

Uji Reliabilitas. Uji reliabilitas dilakukan dengan menggunakan rumus cronbach's alpha. Uji signifikasi dilakukan pada taraf $\alpha=0,05$ atau 5\%.

\begin{tabular}{|r|r|r|}
\hline $\begin{array}{c}\text { Cronbach's } \\
\text { Alpha }\end{array}$ & $\begin{array}{c}\text { Cronbach's } \\
\text { Alpha Based on } \\
\text { Standardized } \\
\text { Items }\end{array}$ & N of Items \\
\hline .909 & .968 & .954 \\
\hline
\end{tabular}

Dari tabel output diatas diketahui adanya $\mathrm{N}$ of items (banyaknya butir atau item pertanyaan) ada 18 buah pertanyaan dengan nilai Cronbach's alpha sebesar 0,909. Karena nilai Cronbach's alpha 0,909 > 0,800. 0,800 merupakan ketentuan nilai Cronbach's alpha yang sangat kuat. Artinya jika nilai yang didapat > 0,800, maka sebagai dasar dalam pengambilan keputusan reliabilitas diatas, dapat disimpulkan bahwa semua item pertanyaan yang tercantum dalam angket adalah konsisten atau reliable. Namun jika nilai yang didapat $<0,800$ maka tidak konsisten atau tidak reliable. Dan tabel output diatas telah memberikan gambaran tentang nilai statistic untuk ke 18 pertanyaan angket. Perhatikan pada kolom "Cronbach Alpha if item deleted" dalam tabel ini diketahui nilai Cronbach's alpha untuk ke 18 soal adalah $>0,800$. Dasar pengambilan keputusan dalam uji reliabilitas adalah jika nilai Chronbach's Alpha > r table maka kuesioner dinyatakan reliable. Sedangkan apabila jika nilai chronbach's alpha < $\mathrm{r}$ table maka kuesioner dinyatakan tidak reliable maka dapat disimpulkan bahwa ke 18 pertanyaan angket reliabel.

Nilai aktual (performance) menunjukan penilaian kualitas pelayanan yang diterima responden. Berikut contoh perhitungan nilai performance untuk pertanyaan atribut 1 dari hasil rekapitulasi data 18 koresponden. Data diambil dari Tabel II

$$
\begin{aligned}
\sum x i & =(1 \times 5)+(2 \times 3)+(3 \times 4)+(4 \times 12)+(5 \times 12) \\
& =5+6+12+48+60 \\
& =131 \\
\overline{x l} & =\frac{\sum \mathrm{Xi}}{n}
\end{aligned}
$$




$$
\begin{aligned}
& =\frac{131}{18} \\
& =7,3
\end{aligned}
$$

Nilai harapan menunjukan penilaian kualitas pelayanan yang diterima responden. Berikut contoh perhitungan nilai harapan untuk pertanyaan atribut 1 dari hasil rekapitulasi data 18 koresponden. Data diambil dari Tabel III

$$
\begin{aligned}
\sum x i & =(1 \times 6)+(2 \times 1)+(3 \times 2)+(4 \times 8)+(5 \times 19) \\
& =6+2+6+32+95 \\
& =141 \\
\overline{x l} & =\frac{\sum \times i}{n} \\
& =\frac{141}{18} \\
& =7,8
\end{aligned}
$$

Perhitungan nilai Service Quality dapat dihitung dengan rumus berikut :

Service Quality Score = Nilai Aktual - Nilai Harapan

TABEL VI

NILAI GAP (SERVQUAL SCORE)

\begin{tabular}{|c|c|c|c|}
\hline \hline Pertanyaan & Aktual & Harapan & $\begin{array}{c}\text { Gap (Servqual } \\
\text { Score })\end{array}$ \\
\hline Atribut 1 & 7,3 & 7,8 & $-0,5$ \\
\hline Atribut 2 & 7,9 & 8,6 & $-0,7$ \\
\hline Atribut 3 & 5,8 & 6,4 & $-0,6$ \\
\hline Atribut 4 & 7,2 & 7,7 & $-0,5$ \\
\hline Atribut 5 & 6,5 & 7,3 & $-0,8$ \\
\hline Atribut 6 & 3,9 & 7,7 & $-3,8$ \\
\hline Atribut 7 & 7,2 & 8,2 & -1 \\
\hline Atribut 8 & 7,7 & 8,7 & -1 \\
\hline Atribut 9 & 6,8 & 6,9 & $-0,1$ \\
\hline Atribut 10 & 6,2 & 8,9 & $-2,7$ \\
\hline Atribut 11 & 8,7 & 6,7 & 2 \\
\hline Atribut 12 & 5,8 & 7,4 & $-1,6$ \\
\hline Atribut 13 & 7,1 & 7,6 & $-0,5$ \\
\hline Atribut 14 & 7,2 & 6,9 & 0,3 \\
\hline Atribut 15 & 6,6 & 5,6 & 1 \\
\hline Atribut 16 & 5,3 & 5,9 & $-0,6$ \\
\hline Atribut 17 & 5,4 & 8 & $-2,6$ \\
\hline Atribut 18 & 7,3 & 6,1 & 1,2 \\
\hline Rata-rata & 6,7 & 7,4 & $-0,7$ \\
\hline & Gap Maksimum & 2 \\
\hline Gap Minimum & & $-3,8$ \\
\hline \hline
\end{tabular}




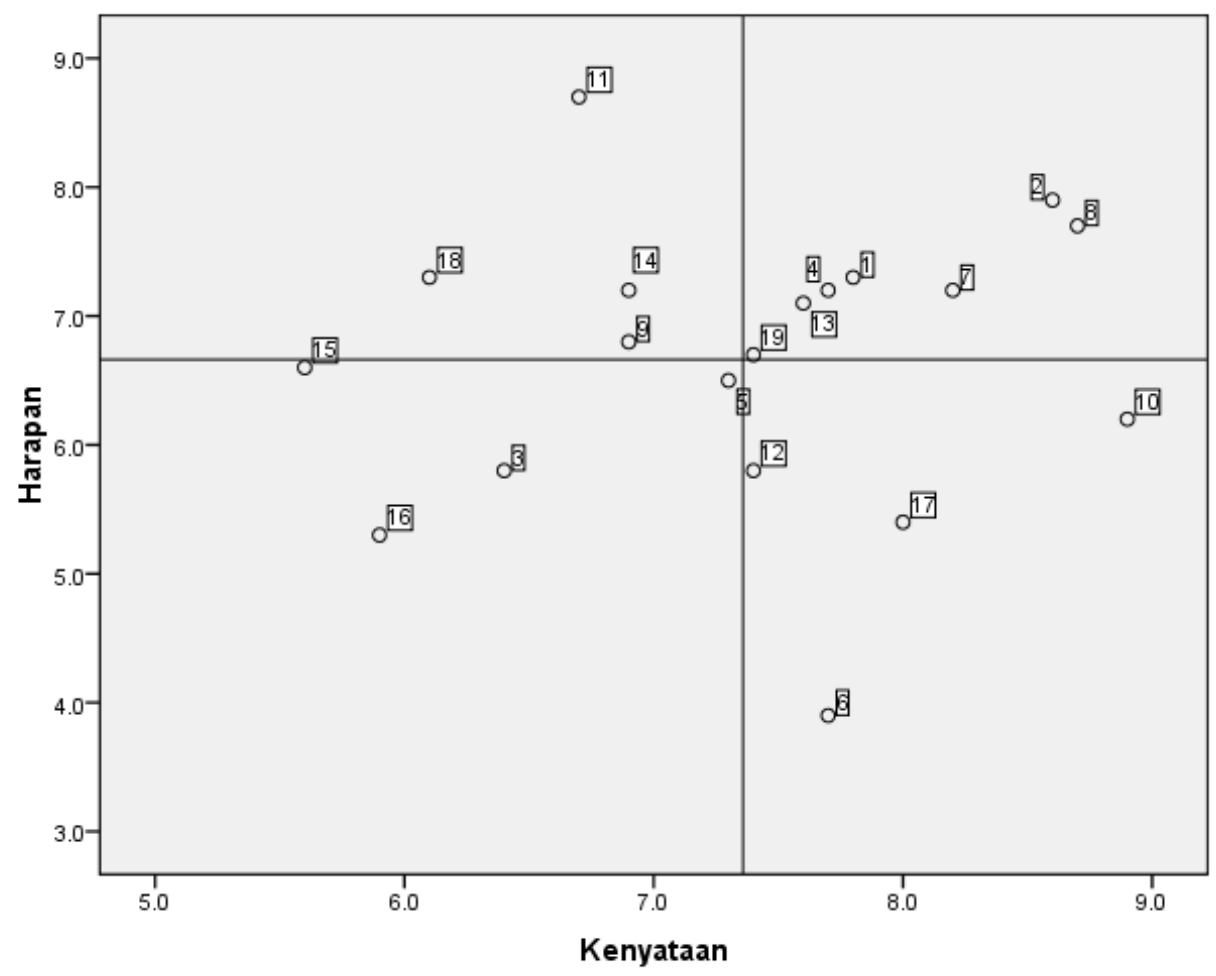

Gambar 2 Diagram IPA (Importance Performance Analysis)

Dari gambar diagram IPA (Importance Performance Analysis) diatas menunjukan kepuasan Taruna secara keseluruhan terhadap fasilitas yang ada di perpustakaan AAU [5]. Hal ini dapat dilihat dari diagram IPA yang ada. Gap tersebut terbagi menjadi 4 bagian yaitu :

a. Pada kuadran I menunjukkan faktor atau atribut yang dianggap mempengaruhi kepuasan konsumen, tetapi pada kenyaataannya faktor atau atribut ini belum sesuai dengan harapan pelanggan dimana tingkat kepuasan yang diperoleh masih rendah. Atribut atribut yang termasuk dalam kuadran ini adalah :

(9) Perpustakaan belum memiliki kecepatan dalam pelayanan kepada pemustaka.

(11) Buku buku yang terdapat di perpustakaan belum lengkap.

(14) Perpustakaan belum menyediakan peralatan kantor yang memadai seperti alat tulis, printer dan mesin fotocopy.

(18) Petugas perpustakaan belum bisa menjalin hubungan baik dengan pemustaka.

b. Pada kuadran II ini menunjukkan unsur jasa pokok yang telah berhasil dilaksanakan perusahaan, untuk itu wajib dipertahankannya dan dianggap sangat penting dan sangat memuaskan. Atribut atribut yang termasuk dalam kuadran ini adalah :

(1) Perpustakaan memiliki petunjuk judul dan jenis buku yang lengkap.

(2) Perpustakaan memiliki referensi lain seperti majalah dan koran.

(4) Petugas perpustakaan memiliki ketelitian dalam melayani pemustaka.

(7) Penataan buku sudah sesuai sehingga mudah ditemukan.

(8) Perpustakaan menyediakan denah tata letak buku.

(13) Petugas perpustakaan memiliki penampilan yang rapi.

c. Pada kuadran III ini menunjukkan beberapa faktor yang kurang penting pengaruhnya bagi konsumen, dan pada kenyaatannya kinerja yang dihasilkan tinggi. Atribut atribut yang termasuk dalam kuadran ini adalah :

(3) Petugas perpustakaan melayani dengan bahasa yang sopan.

(5) Petugas perpustakaan memiliki pengetahuan yang luas tentang buku buku.

(15) Petugas perpustakaan melayani dengan sikap yang ramah. 
(16) Petugas perpustakaan memiliki etika yang baik ketika berkomunikasi dengan pemustaka.

d. Pada kuadran IV menunjukkan faktor yang mempengaruhi konsumen kurang penting, akan tetapi pelaksanaannya berlebihan. Dianggap kurang penting tetapi sangat memuaskan. Atribut atribut yang termasuk dalam kuadran ini adalah :

(6) Perpustakaan memiliki jam operasional yang sesuai dengan keinginan pemustaka.

(10) Petugas perpustakaan merespon dengan cepat dalam menanggapi pertanyaan dari pemustaka.

(12) Perpustakaan memiliki lingkungan yang bersih.

(17) Petugas perpustakaan dapat memahami kebutuhan pemustaka seperti memberi informasi tentang buku buku.

\section{KESIMPULAN}

Kesimpulan dari penelitian ini adalah:

1. Hasil penelitian menunjukan bahwa penilaian fasilitas perpustakaan sesuai dengan baik atau tidaknya kualitas fasilitas yang diberikan kepada Taruna. Kualitas kepuasan terhadap fasilitas dibangun atas adanya perbandingan dua variable utama yaitu harapan Taruna atas fasilitas yang mereka terima dengan fasilitas yang sesungguhnya [5]. Namun demikian dari hasil analisis diatas, pelayanan fasilitas yang diberikan perpustakaan AAU belum menunjukan hasil yang memuaskan terhadap Taruna yang menggunakan fasilitas di perpustakaan AAU, dikarenakan masih ada Taruna yang belum merasa puas terhadap fasilitas perpustakaan AAU serta pelayanan yang diberikan petugas perpustakaan dinilai masih kurang memuaskan, yaitu ; perpustakaan belum memiliki kecepatan dalam pelayanan kepada pemustaka, buku buku yang terdapat di perpustakaan belum lengkap, perpustakaan belum menyediakan peralatan kantor yang memadai seperti alat tulis, printer dan mesin fotocopy, dan petugas perpustakaan belum bisa menjalin hubungan baik dengan pemustaka [11].

2. Berdasarkan hasil analisa gap (kesesuaian antara aktual dengan harapan) tiap dimensi, dapat disimpulkan variable yang paling memuaskan Taruna diantara variable yang ada yaitu variable yang memiliki nilai gap paling kecil yaitu variabel aktual 6,7 dan variabel harapan 7,4 sehingga masih terdapat gap -0,7. Gap ini terjadi akibat tidak terpenuhinya harapan Taruna dengan fasilitas yang disediakan oleh perpustakaan Akademi Angkatan Udara.

\section{UCAPAN TERIMA KASIH}

Pada kesempatan kali ini, ucapan terima kasih disampaikan kepada kinerja seluruh tim sehingga naskah penelitian ini dapat diterbitkan. Pada dasarnya penelitian ini masih jauh dari kata sempurna sehingga ke depan masih membutuhkan penyempurnaan pada penelitian berikutnya. Tim peneliti akan menerima segala macam kritik yang membangun bagi terwujudnya naskah penelitian yang lebih baik di masa mendatang. Sebagai bagian dari kolaborasi/kerjasama penelitian antar dosen di AAU, diharapkan akan mampu berbagi pengetahuan untuk meningkatkan kualitas dan kesepahaman teori penelitian AAU di masa mendatang. Selain itu, penelitian ini juga bertujuan untuk meningkatkan ketrampilan dan kredit point bagi dosen sehingga akan meningkatkan akreditasi Lembaga. Oleh karena itu, kerjasama seperti ini diharapkan dapat dilaksanakan dalam berbagai penelitian berikutnya. Kolaborasi yang selaras, terarah dan efektif serta efisien akan mampu memberikan arah yang jelas bagi perkembangan prodi di masa mendatang. 


\section{REFERENSI}

[1] Direktorat Sekolah Dasar, "Menyiapkan Pendidik Profesional Di Era Society 5.0," 3 februari 2021, 2021.

[2] A. Sebastian S, A. S. Junior, A. Josefanny S, N. E. Kezia and S. Hendra, "Peran Pendidikan dalam Perkembangan Era Society 5.0," Jakarta, 2021.

[3] Akademi Angkatan Udara, Program Taruna Gemilang, 1 ed., Yogyakarta, 2021.

[4] D. Sinaga, in Mengelola Perpustakaan Sekolah, Jakarta, Kreasi Media Utama, 2007, p. 15.

[5] F. R. Gerson, in Mengukur Kepuasan Pelanggan, Jakarta, Penerbit PPM, 2017.

[6] V. Parasuraman, Zeithmal and A. Malhotra, "E-S-QUAL A Multiple-Item Scale for Assesing Electronic Service Quality," in Journal of Service Research, 2005.

[7] V. Parasuraman, Zeithmal and L. Berry, in Delivering Quality Service : Balancing Customer Perception and Expectatons, The Free Press, 1990.

[8] Alexandria and A. Curry, "Managin Service Quality," Service improvements in public services using servqual, vol. 11, no. 6, pp. 389-401, 2001.

[9] P. Suwignjo, "Sistem Pengukuran Kinerja: Sejarah Perkembangan dan Agenda Penelitian ke," in Proceeding Seminar Nasional Performance Management, Hotel Wisata, Jakarta, 2000.

[10] F. Tjiptono, in Service Manajemen Mewujudkan Layanan Prima, Yogyakarta, CV Andi Offset, 2012.

[11] S. Muchyidin, Mihardja and I. Sasmita, in Perpustakaan, Bandung, PT Puri Pustaka, 2008, pp. 41-42.

[12] A. Buxbaum, "Library Services," Jakarta, Murni Kencana, 2004, p. 12.

[13] P. K. Kotler, Manajemen Pemasaran Jilid I Edisi 12, Jakarta: PT. Indeks, 2007.

[14] Sidabutar and D. Lesmina Hariati, in Studi Identifikasi Faktor Faktor yang Mempengaruhi Kepuasan Kerja Pada Badan Narkotika Nasional Provinsi Sumatra Utara, Universitas Medan Area, 2016. 